\title{
QUEEN'S
UNIVERSITY
BELFAST
}

\section{Gender, work and care in policy and practice: Working mothers' experience of intergenerational exchange of care in South Korea}

Sung, S. (2018). Gender, work and care in policy and practice: Working mothers' experience of intergenerational exchange of care in South Korea. Critical Social Policy, 38(3), 589-608.

https://doi.org/10.1177/0261018317746042

\section{Published in:}

Critical Social Policy

\section{Document Version:}

Peer reviewed version

Queen's University Belfast - Research Portal:

Link to publication record in Queen's University Belfast Research Portal

Publisher rights

(c) The Author(s) 2017. This work is made available online in accordance with the publisher's policies. Please refer to any applicable terms of use of the publisher.

\section{General rights}

Copyright for the publications made accessible via the Queen's University Belfast Research Portal is retained by the author(s) and / or other copyright owners and it is a condition of accessing these publications that users recognise and abide by the legal requirements associated with these rights.

Take down policy

The Research Portal is Queen's institutional repository that provides access to Queen's research output. Every effort has been made to ensure that content in the Research Portal does not infringe any person's rights, or applicable UK laws. If you discover content in the Research Portal that you believe breaches copyright or violates any law, please contact openaccess@qub.ac.uk. 


\title{
Critical Social Policy \\ Article
}

\section{Gender, work and care in policy and practice: Working mothers' experience of intergenerational exchange of care in South Korea}

\begin{abstract}
This article aims to uncover working mothers' experiences in relation to intergenerational exchange of care and support in South Korea. It examines the impact of Confucian gender ideology on the operation of intergenerational reciprocity within the Korean family. Increasing numbers of working mothers make intergenerational exchange of care between working mothers and their family members an important issue. Although studies have focused on the importance of the Confucian virtue of filial piety in intergenerational support, little research has explored the influence of Confucian gender ideology on working mothers' experiences of intergenerational exchange from a gender perspective. This article aims to fill this research gap by exploring the experiences of Korean working mothers in the intergenerational exchange of care. It draws on qualitative semi-structured interviews with 30 married women in paid employment in Seoul, Korea, carried out in 2014. This article argues that traditional gender expectations of married women's responsibility for parents-in-law persist regarding intergenerational reciprocity, despite recent development of policies for care.
\end{abstract}

Key words: Confucian culture, Gender ideology, Gender inequality, Intergenerational exchange, Working mothers

\section{Introduction}

This article aims to explore working mothers' experiences of intergenerational exchange in relation to care in Korea ${ }^{i}$ from a gender perspective. It will examine the extent to which Confucian gender ideology impacts on the ways in which intergenerational reciprocity works within the Korean family. Intergenerational exchange refers to "the reciprocal provision of support between elder parents and their adult children or grandchildren, such as domestic help, financial aid, and informal caregiving' (Grundy, 2007, in Zuo et al., 2011:S30). Intergenerational support flows two ways - from the older to younger generation, and from young adults to the older generation. While adult children offer care and financial support for older parents, parents themselves often provide childcare for grandchildren. With the growing number of working mothers, family support with care has come to the fore (KOSIS, 2012), as it is likely to be women providing care and hands-on services for family members. Therefore, the notion of intergenerational exchange of support flowing between working mothers and their mothers/mothers-in-law and how the care exchange is reciprocated in practice becomes a crucial issue to explore. 
Several explanations for intergenerational support have been suggested by researchers: gender ideology, reciprocity and hierarchical principles (Lin et al., 2003). With a focus on the relationship between gender ideology, reciprocity, responsibility and hierarchical principles and how they are interconnected, this article will examine the gender dimension of intergenerational exchanges of care. Gender ideology and family reciprocity seem to be strongly associated with the Confucian cultural value of filial piety/responsibility and traditional gender roles within the Korean family. In this article, intergenerational reciprocity will be examined in two ways: exchange of care between respondents and their parents/parentsin-law (often mothers/mothers-in-law), and financial support flows from parents/parents-inlaw to adult children and vice versa. For example, are working mothers more likely to take responsibility for mothers/mothers-in-law who are providing or have provided them with childcare support? Do working mothers feel more responsible for their parents/parents-in-law in old age if they have received financial support from them currently or in the past?

When examining intergenerational reciprocity in Korea, it is essential to discuss the impact of the Confucian culture of filial piety and traditional gender roles. Confucianism has long been identified as Korea's main cultural heritage (Schwarz, 2006). According to Confucian tradition, sons (particularly the eldest) play a critical role in the Korean family in providing intergenerational support for older parents, implying the main responsibility of daughters-inlaw is caring for their parents-in-law. Recent social and demographic changes along with policy development may have weakened these Confucian cultural values. The rising number of women in the labour market clearly reflects these changes in Korean society. Nevertheless, men's involvement in unpaid work has not improved greatly, which leaves working mothers with a double burden of work and care.

The influence of the Confucian value of filial piety on intergenerational relations in East Asia, including Korea, has been highlighted before (Lin and Yi, 2011; Schwarz et al., 2006; Sung, 1990; Zhan et al., 2011). Also, some studies examine intergenerational support in Korea, but these focus mainly on quantitative measures such as the household panel survey and the gender and care survey (Joo et al., 2016; Yu, 2016; Yu et al., 2015). Little has been done on the impact of Confucian gender ideology upon working mothers' qualitative experience of the intergenerational exchange of care. This article aims to fill this gap by exploring the 
experiences and views of working mothers of intergenerational exchanges of care between parents/parents-in-law and themselves.

\section{Working Mothers in South Korea: Understanding Intergenerational Exchange in a Confucian Society}

\section{Social and demographic changes vs continuity in gender roles}

Korea has undergone transformations in socio-economic, demographic and cultural trends. Rapid economic growth since the 1960s increased women's participation in the labour market. In particular, married women's participation rose from 40 per cent in 1985 to 52.8 per cent in 2015 (KOSIS, 2016). Recent demographic changes further indicate the need for substantial public policies to enable women and men to balance work and care. The number of children born to women aged 15 to 49 has fallen from an average of 4.5 in 1970 to 1.19 in 2013, the lowest among OECD countries (OECD, 2016c). This rapid decline in fertility reflects the considerable pressures that mothers and fathers encounter in Korea, due to low rates of public spending on early education and childcare (Sung, 2014). At the same time, life expectancy at birth continues to increase; on average women can expect to live to 85 or over compared to the OECD average of 83.1 (OECD, 2015). In addition, cultural changes have shifted attitudes towards traditional gender roles to some extent, following changes in the labour market and gender equality legislation (Sung, 2014).

Despite these changes, gender inequalities arising from traditional gender roles persist within Korean families. Korean women living in the midst of cultural transition may feel torn between the values embodied in traditional gender roles and the new value of gender equality. While their growing participation in paid employment indicates societal change, the persistence of gendered notions of women as the primary carer in the family indicates the rootedness of traditional ideas (Sung, 2014). In particular, men's involvement in domestic/care work has not significantly improved relative to women's participation in paid work. Working mothers still tend to take more responsibility for family care, despite their involvement in paid work (Joo et al., 2016). In this respect, family support for childcare seems particularly important for Korean women in paid work. A lack of good quality, affordable childcare often leads dual-earner families to rely on informal care provided by grandparents and other family members (Yu et al., 2015). Grandparents, especially grandmothers, play an important role in providing childcare. The proportion of grandparents providing care for children aged 0-2 increased from 
23.6 per cent in 2004 to 37.8 per cent in 2012; for children 3-5 years old it increased from 20.2 per cent to 31.5 per cent (Yu et al., 2015). According to $\mathrm{Yu}$ (2016), the main reasons why grandparents decided to look after grandchildren were to support their children to continue paid employment (67\%), and the lack of good quality and reliable childcare places/institutions $(42.8 \%)$.

In terms of private financial transfers, about 41 per cent of older people (those aged 50 and over) in Korea received cash from their children, a much higher proportion than in other OECD countries, whilst only 9 per cent gave cash to their children (OECD, 2012). Therefore, adult children in Korea tend to provide more financial assistance to their older parents than in other OECD countries. On the other hand, the number of grandmothers providing childcare for grandchildren continues to increase due to married women's increasing participation in the labour market (Yu, 2016).

Intergenerational exchange of care between working mothers and their own mothers/mothersin-law reflects women's primary responsibility for childcare and eldercare, which is closely related to gender ideology. Therefore, it is necessary to examine the explanations for intergenerational exchange/support from a gender perspective in the context of Korean family.

\section{Confucian Gender Ideology}

The gendered notion of care as woman's work has been challenged by feminist scholars (Graham, 1983). However, the traditional idea of family care as women's responsibility prevails in the Korean family despite women's increasing participation in paid work. 'Gender ideology' explains the gendered division of labour in the family as a gender-based expectation, internalised by individuals through socialisation (Lin et al., 2003; Ross, 1987). In Korea, gender ideology is strongly influenced by Confucian tradition, which clearly differentiates the role of men and women within the family. In Confucian patriarchy, family members were placed according to the hierarchical order: the hierarchy between parents and children, and between husband and wife, and their roles were clearly defined. According to the Confucian Book of Rites, the concepts of 'inside' and 'outside' spheres applied to familial relationships, similar to the Western concept of 'private' and 'public' spheres. 'Inside' is women's sphere involving domestic and care work, while 'outside' indicates the non-domestic and political/social sphere outside the home (Lee, S., 2005:82). While such traditional distinctions between 'inside' and 'outside' may seem less apparent in contemporary Korea with the 
growing number of women in the workforce, the Confucian hierarchical familial relationship persists to some degree as women continue to take more responsibility for domestic and care work, despite their involvement in paid employment.

In respect to intergenerational support, men are considered to be providers while women are caregivers. Therefore, in Korea, sons often provide financial support for older parents, when sons' wives (daughters-in-law) are responsible for household chores or personal care for parents-in-law (Sung, 2003, 2014). Therefore, the division of gender-specific tasks in the family may occur between married sons and their spouses, rather than between married sons and married daughters (Sung, 2013).

\section{Reciprocity, responsibility and hierarchical principles: The impact of Confucian gender ideology}

The concept of reciprocity explains that 'the extent to which adult children help their parents is based on the parent's past investment in them' (Gouldner, 1960; Lin et al., 2003:186). In this article, grandparents providing care for grandchildren is considered a form of investment in/support for their adult children, as it forms an important part of the support system for working mothers in Korea. Reciprocity here is examined both as the exchange of care-giving roles between adult children and parents and as the extent of financial support for parents in old age. In particular, this article will examine the flow of care from grandparents to grandchildren and from adult children to older parents, and how that flow is interrelated or exchanged within the Korean family.

According to Schwarz et al. (2006), reciprocity plays a significant role in the Confucian concept of filial piety in Korea, as adult children have an obligation to return to their parents the care and support they received in the past. Schwarz et al. (2010:236) also highlight the importance of the 'culture-specific meaning of reciprocity' in intergenerational support. In Korean families, the traditional gender roles favoured by Confucian culture are embedded in the practise of intergenerational reciprocity, as married women tend to be more responsible for looking after their parents-in-laws than their own parents, whether they receive(d) support for childcare from their parents/parents-in-law or not (Lee, J., 2005).

While reciprocity plays a crucial role in intergenerational care, responsibility based on Confucian gender ideology is another key component in the practice of care. According to 
Tronto (2011), responsibility is one of the key ethical elements of care. It is a term 'embedded in a set of implicit cultural practices', and can have different meanings 'depending upon one's perceived gender roles, family status and culture' (Tronto, 1993:132-133). In the context of the Korean family, the Confucian moral code and cultural practice of filial responsibility require parents-in-law to be the first priority of married women in terms of both caring and financial support, although they often feel emotionally closer to their natal families (Lee, J., 2005). This gendered practice of care seems to persist even in dual-earner households.

As Marshall et al (1987, cited from Izuhara 2010:6) suggest, 'the nature of caring relationship rests on a delicate balance between reciprocity, affection and duty'. Indeed, there is a complex interconnection between reciprocity and responsibility in the intergenerational exchange of care. Informed by Confucian gender ideology, the gendered practice of filial responsibility in Korea has an impact on the ways in which married women reciprocate the exchange of care with their parents/parents-in-law. For example, reciprocity can reinforce the sense of responsibility when reciprocating care with their mothers-in-law if their mothers-in-law provide childcare for their children. However, when it comes to exchanging care with their own mothers, reciprocity may be undermined by the sense of filial responsibility for their parents-in-law instilled by Confucian cultural and normative practice of eldercare in Korea.

Hierarchical principles of intergenerational support impose a traditional normative preference structure for female relatives in relation to the decision model on care provision (Walker, 1996). In Korea, sons traditionally have provided financial assistance while daughters-in-law have served as primary caregivers (Lee, S., 2005). Hence, daughters-in-law take precedence over daughters in terms of caring responsibilities, as sons are regarded in Confucian patriarchy as the main providers for parents in their old age (Sung, 2013). Parents in old age are more likely to choose to live with their married sons than with their married daughters. When there is more than one son in the family, the eldest son typically will take primary responsibility for his parents in old age (Lee, J., 2005). This indicates that the hierarchical nature of intergenerational reciprocity is closely related to Confucian gender ideology, as it reflects not only beliefs about reciprocity between adult children and older parents but also expectations about the gender appropriateness of caring tasks. 


\section{Have Recent Policies Supported Working Mothers? Child and Elder Care}

\section{Policies}

Although the Korean economy has grown rapidly, the government continues to focus more on economic development than on welfare policy reform. Nevertheless, since the economic crisis in 1997, welfare policy in Korea has become more egalitarian, shifting from selective to more universal forms (Kwon, 2009). The National Health Insurance and public assistance programmes were reformed and became more generous (Sung, 2003, 2014). Equal opportunity legislation also has been reformed several times since 1987, and the reform of family law in 2008 resulted in abolishing the 'ho-ju' (male head of family) system (Hong, 2008, in Sung, 2014). Furthermore, work-family balance policies, which are part of the Equal Employment and Support of Work-family Balance Act, were reformed in 2014 and 2016, with particular focus on childcare-related leave (MOLEG, 2016). Maternity leave (90 days) and benefits have become more generous, offering 100 per cent income replacement of monthly wages for 60 days and employment insurance cover up to 1,350,000 won (£920) for the remaining 30 days (MOEL, 2016). Paternity leave (3-5 days), previously unpaid, is now paid for three days. Parental leave also became more generous in terms of duration (1 year for children under eight years old) and pay. Parental leave pay now replaces 40 per cent of a monthly wage up to $1,000,000$ Korean won (approximately £685) and no less than 500,000 won (£343) per month (KWDI, 2016a). The reforms of 2016 also introduced 'daddy month'. Like Sweden's 'daddy quota' policy, 'daddy month' enables mothers and fathers to take parental leave consecutively. Fathers who avail of the 'daddy month' option are entitled to 1,500,000 won (£1027) per month or 100 per cent of their monthly wage, whichever is lower (KWDI, 2016b).

Although the terms of parental leave have improved, uptake by fathers remains low. Only 5.6 per cent of men took parental leave in 2015 compared to 94.4 per cent of women, among those who are eligible for parental leave (KWDI, 2016c). In a study by Hong and Lee (2014), fathers identified two main obstacles to using leave: financial loss and the organizational culture of the workplace. The low level of parental leave pay can result in reduced household income, whilst a culture that portrays men who take leave as less committed to work can be disadvantageous for promotion and pay. Moreover, the gendered assumption that childcare is women's/mothers' work persists, as maternity, paternity and parental leave still come under the 'maternity protection' scheme; changing the name to 'parental rights' would be more appropriate (Sung, 2003). Moreover, total public expenditure on early childhood education and care in Korea 
remains significantly lower than in Nordic and western European countries (just over $0.8 \%$ of GDP), albeit slightly higher than the OECD average of just over 0.7 per cent (OECD, 2016a). Reliance on private institutions at the pre-primary level is significantly higher in Korea than the OECD average. The percentage of pupils enrolled in private institutions was 81 per cent in 2014, compared to the OECD average of 33 per cent (OECD, 2016b). Lack of publicly funded childcare can make childcare expensive, lead to a lack of facilities (Sung, 2014), and increase reliance on informal care. Indeed, since 2014, the growing number of dual-earner families relying on informal childcare has focused attention on research on policy support for grandparents providing childcare (Lee et al., 2015; Yu, 2016; Yu et al., 2015). Yu (2016) proposed introducing childcare allowances for grandparents, but the issue of providing cash benefits to grandparents for childcare provision continues to be controversial for its potential to perpetuate gender disparities in care work and place responsibility for childcare on the family.

Since the 1990s, as the proportion of older people has grown, policies for eldercare have become an important issue (Statistics Korea, 2011). Welfare provision for older people has improved gradually since 2008, particularly after reforms in 2010 and 2015, which have focused mainly on elder abuse and home care services. The introduction of Long-Term Care (LTC) Insurance in 2008 is particularly notable as it acknowledges care as both a societal and a familial responsibility (Kim, 2016). Although policies for eldercare have improved, they still fail to address the problem of sufficient support for older people and those (usually women) who care for them. The socialization of care has not been achieved through the adoption of LTC Insurance, as it derived not from the need to attain socialization of care but from urgent social and economic pressures, such as low fertility rates, unemployment and a lack of care services (Kim, 2016). The Confucian virtue of 'filial piety' is still accentuated in welfare provision for the elderly (Sung, 2014). The 2015 reformed policy continues to place emphasis on 'maintaining the family system' and the importance of 'the enhancement of the spirit of respect for the elderly and filial piety' (MOLEG, 2017: Chapter 3, Article 1).

Despite recent policy developments in both child and elder care, the notion of care as a family responsibility has not been greatly challenged in Korea. It is also doubtful that the trend is towards the socialization of care, as growth-oriented economic policies continue to predominate (Sung, 2014). Korean policies on care reflect the transitional period in which traditional and egalitarian ideas on gender roles co-exist. For example, the emphasis on fathers' 
role in childcare represents egalitarian ideas, while the 'maternity protection' scheme mirrors women's primary role as carers. Eldercare provision particularly reflects the Confucian ideology of filial responsibility, emphasising family responsibility for care, which often becomes women's responsibility. Low uptake of parental leave by fathers indicates that a cultural shift is necessary as well as policy development to achieve gender equality within the family and wider society.

\section{Research Methods}

Qualitative semi-structured interviews were employed to explore the experiences of working mothers in the intergenerational exchange of care. Thirty married women in paid employment were interviewed in 2014 in Seoul, South Korea. All interviewees were married with children (dependent or non-dependent) and ranged in age from 19 to 60 . They were drawn equally from younger (19-40 years old) and older (41-60 years old) age groups. The majority were highly educated, holding undergraduate or postgraduate degrees; only three had just a high school diploma. Participants were mainly from lower to upper middle-income families. The interviews initially focused on the experiences of women reconciling work and family rather than the issue of intergenerational exchanges of care. However, because the interview questions included how working mothers manage childcare and eldercare responsibilities, the intergenerational exchange of care between working mothers and their mothers/mothers-in-law became apparent, as family support for childcare seemed important to participants. Younger participants with young children were asked about their current experiences of childcare arrangements, whilst older participants with grown-up children were asked about their past experiences. All participants were asked about their experiences of eldercare. Participants who had no experience of eldercare were asked to anticipate what might happen when their parents/parents-in-law were older, whereas participants who had experience were asked about their past or current experiences. Thematic analysis was used to analyse the interview data. Framework matrices that display cases and themes were constructed to highlight important themes by cases, a useful method for ordering and analysing qualitative data (Ritchie et al., 2003). Pseudonyms were used to maintain confidentiality and anonymity.

\section{Working mothers' experience of intergenerational exchanges of care: Reciprocity, responsibility and Confucian gender ideology}


In relation to intergenerational exchange of care, most respondents (21 out of 30 ) had some childcare support from their mothers or mothers-in-law. When they received help with childcare from their mothers-in-law, they tended to reciprocate by providing eldercare or financial support. When received from their own mothers, however, such help did not seem to be reciprocated in the same way. Intergenerational reciprocity between the respondents and their mothers-in-law was often based on the 'feeling of responsibility/obligation' rooted in Confucian gender ideology, whilst respondents often described 'strong emotional ties' or a 'comfortable relationship' rather than 'obligation' regarding their own mothers.

\section{Exchanges of care with mothers-in-law}

About a third of respondents (10 out of 30) said that their mothers-in-law helped with childcare when their children were young (aged 0-8). In several cases they lived with their mothers-inlaw or lived nearby to make childcare easier; others said they did so mainly to fulfil their obligation as daughters-in-law. Thirty-eight-year-old Mini, for example, works full-time as a nurse. With two young children, she found it helpful to live with her mother-in-law, although she said it could be stressful at times. Mini and her husband have been living with her motherin-law for 10 years and support her mother-in-law financially every month to show their gratitude. Recently, she also has been caring for her mother-in-law in the evening when she returns from work, as her mother-in-law has been sick for the past three months. She finds doing both paid work and care work difficult to cope with, but she feels obliged to look after her mother-in-law, considering all the childcare her mother-in-law provided.

Yuna's experience also illustrates reciprocity between daughter-in-law and mother-in-law. Yuna is 33 years old, has two sons and works full-time in a private company. Yuna's motherin-law looked after her son for two years; she also hired a babysitter to help her mother-in-law with childcare. Yuna said she took much more responsibility for her parents-in-law, whom she supports financially every month and visits more frequently than her own parents. When asked why she did more for her parents-in-law than for her own parents, she explained:

It's because my parents-in-law have certain expectation from my husband as their eldest son and me as their daughter-in-law... I am following the tradition. I guess I adopted traditional gender roles, although I don't like the idea. 
Yuna lived near her parents-in-law and said she would have to live with them when they got older. Highlighting the importance of adult children taking responsibility for older parents, she said that adult children should mainly be responsible for caring for parents in old age with government support for eldercare coming second, though she welcomed the development of government provision.

The importance of being the eldest daughter-in-law also was accentuated, especially when husbands and parents-in-law hold the traditional views on gender roles. Eldest daughters-inlaw and only daughters-in-law felt obliged to take responsibility for their parents-in-law, whether they received support with childcare from their mothers-in-law or not. This emphasis on the filial responsibility of the eldest son and daughter-in-law indicates the Confucian hierarchical principles in intergenerational obligations, which was also evident in Jae Kyung Lee's study (2005) on women and the Korean family.

About a half of participants (aged 33-55) had experienced living with their parents-in-law. Three were still living with them at the time of the interviews; only one had experience of living with her own parents. None of these respondents regarded the experiences of living in the same house with their mothers-in-law as pleasant, as a daughter-in-law is expected to obey a mother-in-law. Mini, for example, described her experience of living with her mother-in-law as 'mentally stressful and emotionally intimidating', although she greatly appreciated that her mother-in-law helped her to look after her five-year-old daughter. Her main concern was with her husband not engaging with or being allowed to do much housework or childcare, which is regarded as women's/mother's work in the Korean family. Mini's experience demonstrates the extent to which a mother-in-law can interfere in the relationship between husband and wife, as a son's obedience to his parents takes priority over his relationship with his wife (Sung, 2014). Nevertheless, Mini said she might have to continue to live with her mother-in-law whether she likes it or not, because of the childcare her mother-in-law provided.

The evidence from the interviews suggests that intergenerational reciprocity seems to work when mothers-in-law look after the grandchildren, though the level of commitment to/responsibility for caring for mothers-in-law might differ depending on the support they provide. For example, respondents who had help with childcare from their mothers-in-law were more likely to express a stronger 'feeling of obligation' towards them, compared to those who had received no help. They also appeared more committed to the idea of living with their 
mothers-in-law in old age, whether they liked the idea or not. By contrast, respondents whose mothers-in-law had not helped with childcare appeared to prefer the option of living nearby to their parents-in-law/mothers-in-law in order to look after them in old age rather than living in the same house, but were not sure if the option would be welcomed by their husbands or parents-in-law. Living nearby was a new concept proposed by respondents to facilitate care for their parents-in-law, one which reflects the cultural transition in terms of eldercare arrangements and suggests that the tradition of living with parents-in-law might change in future. Overall, although the level of support they provided varied, most respondents stated that they took more responsibility for their parents-in-law than for their own parents. In fact, none expressed the same level of responsibility and obligation towards their own parents, despite having strong emotional ties to them, and to their mothers in particular. In this case, the findings from this study suggests that intergenerational reciprocity is greatly influenced by the Confucian gender ideology emphasising married women's responsibilities as daughters-in-law.

\section{Exchanges of care with mothers}

More than a third of respondents (11 out of 30) said that their mothers helped with childcare. Three respondents said their children lived with grandmothers during weekdays, while other respondents said their mothers lived nearby to support them. Susie is a highly educated civil servant with two children ( 7 and 4 years old). Although Susie's mother looked after her daughter and son for three years when they were babies, Susie said that she takes more responsibility for her parents-in-law than for her own parents. She also described her parentsin-law as extremely influenced by traditional views on gender roles:

My parents-in-law have very strong Confucian traditional views. They don't even like it if I want to visit my own parents during celebration days (e.g. New Year's Day and the Autumn festival in September). I do much more for my parents-in-law and visit them more often.

According to Susie, she might have to live with her parents-in-law when they got older whether she liked the idea or not. While she felt that it was unfair on her to take more responsibility for her parents-in-law she nevertheless accepted it as is the norm in Korean society.

The case of Gina, a 52-year-old teacher, is especially interesting. Like two other respondents who worked long or unsocial hours or in a highly demanding workplace, Gina saw her children 
only on weekends. This was a short-term strategy, particularly used before the children were of school age, as Gina explained:

My mother looked after my children for five years. My children actually lived together with her for five years during weekdays. They lived with me and my husband only during the weekends.

Although Gina's mother helped her much more with childcare, she still took more responsibility for her parents-in-law, with whom she lived for two years at the beginning of her marriage. When her mother-in-law asked her to quit her job to look after the children, she decided to live apart from her parents-in-law and asked for her mother's help with childcare. Nevertheless, she has been giving more financial support to her parents-in-law and visits them more regularly, as her husband is the only son in the family. She said that her parents refused to take any money from her and were more accommodating to her needs than her parents-inlaw. When asked why she felt more responsible for her parents-in-law, she said they were more demanding:

My parents would be much more understanding and never ask anything from us, while my parents-in-law would expect us to give them support in general (both financial support and caregiving). He is the only son, so they regard it as our responsibility to take care of them.

In most cases, when respondents received childcare support from their own mothers, intergenerational reciprocity of caring for parents in old age did not seem to apply, since their responsibility as daughters-in-law was considered to be more important overall. One respondent also said that both her husband and parents-in-law often have expectations and traditional views on gender roles and often emphasized the importance of being a daughter-inlaw in the Korean family.

More importantly, for married women, living with their own parents appeared to be considered inappropriate or undesirable by both their parents and parents-in-law. In some cases, their husbands also disagreed with the idea. Son's responsibility for their parents in old age remains prevalent, perpetuating daughters-in-law's responsibility for parents-in-law (Sung, 2013). Asked 'how would your parents-in-law react, if you wanted to live together with your 
parents?', most respondents (27 out of 30) said that their parents-in-law 'would not like the idea' or 'would never approve of it' or 'think of it as absurd'. This view was expressed by Bini, a 40-year-old college graduate who has been living with her parents-in-law for 10 years and whose father-in-law particularly emphasized her responsibility, as the eldest daughter-in-law, for caring for her parents-in-law in old age:

My parents-in-law would never allow it.... They will say 'you are the eldest daughterin-law, so you should be responsible for us, not for your parents'. I think my husband would say the same thing.

Only three respondents said that their parents-in-law would not mind the idea of them living with their own parents. In these cases, respondents were receiving childcare support from their mothers, while the mothers-in-law did not want to or could not help with childcare for various reasons (e.g. poor health or lifestyle changes). The fact that respondents used the word 'approval' indicates the level of interference from parents-in-law in both intergenerational support arrangements and relations between married women and their own parents.

In some cases, parents refused to live with their married daughter, even if the option was available. For example, Juha's father-in-law refused his daughter's invitation to live with her, preferring to reside with his son and daughter-in-law. In the Korean family, among older parents considering living with their adult children, sons are preferred to married daughters (Lee, J., 2005). Juha, a middle manager working in a private company with two young children, explained this as an aspect of traditional culture, which strongly affects parents' decisionmaking in terms of intergenerational support, particularly decisions about whom to live with. A Taiwanese study on intergenerational support shows similar findings, confirming older parents' preference for receiving support from sons (Lin et al., 2003). Another four respondents saw it as their brother's responsibility to look after their own parents, explaining that their parents seemed to have higher expectations of their brothers and their brothers' wives than of them. This indicates that hierarchical principles of intergenerational support are influenced by Confucian gender ideology, as older parents seem to prefer receiving support from their sons rather than their daughters.

Two respondents received help with childcare from both their mothers and their mothers-inlaw. Sunmi explained that her mother looks after her two children three days a week and her 
mother-in-law also cares for them three days a week. This arrangement has helped her balance work and care, as she works full-time as a teacher:

My mother-in-law looks after my children for three days, Monday, Tuesday and Wednesday, while my mother helps me with childcare on Friday, Saturday and Sunday. It makes my work-family balance much easier.... I am emotionally more attached to my own parents.... But I might have to live together with my mother-in-law in the future as my husband is the only son, so it's hard to refuse.

Although Sunmi feels more comfortable with her own parents, with whom she has stronger emotional ties, she feels more obligation and responsibility to her mother-in-law. She did not feel the same level of responsibility for her own mother, in spite of the childcare provided by her mother. Similarly, Jae-Kyung Lee's study (2005) suggested that married women were emotionally closer to their own parents but felt more obligation towards their parents-in-law.

\section{Intergenerational Financial Support}

Intergenerational financial support refers to the flow of support from adult children to parents and from parents to adult children. Data from the interviews indicated that financial transfer was predominantly based on gender ideology. For example, most respondents (22 out of 30) said they provide some financial support to their parents-in-law, while only two offered support to their own parents. More than a half gave financial support to their parents-in-law monthly; others did so several times a year. Asked why they provide more financial support to their parents-in-law, respondents stated that their parents-in-law often expect support from them, as it is a son's responsibility to financially support his parents in old age. This practice is common in the Korean family, as Minju explained:

I give more financial support for my mother-in-law. I know that it's unfair but it's just traditional custom in Korea. She is my mother-in-law, so I feel that I should be giving her some financial support. I rarely give money to my parents.... In Korea it [financial support from their son] is kind of expected by parents-in-law. It's hard to break the rules.

Two respondents said they offered financial support to their own parents because either the respondent's mother provided childcare or their parents had a low income. In some cases, 
respondents said that their parents did not accept any financial support from them, as they did not want to place any burden on their daughters.

Interestingly, three respondents said that they received some financial help from their parents, citing debts and low income as the primary reasons for this. Although none of the three said their parents-in-law supported them financially, all said that they felt more responsible for their parents-in-law, the main reasons being 'childcare provided by their mothers-in-law' and 'the illness of father-in-law'. Thus, they had to live either with or near to their parents-in-law to look after them. Although the respondents received financial support from their own parents, they did not say that they feel obliged to live with or nearby to care for them in old age. The obligation was rather directed towards their parents-in-law, as was also evident in Sang-Wha Lee's study (2005) on Confucian patriarchy.

\section{Working mothers' views on living with their adult children in the future}

Asked about their future plans, most respondents (28 out of 30) said they did not wish to live with their adult children in future when they were older. They suggested that there will be a generation gap between their children and themselves. Also, cultural changes mean that the traditional virtue of 'filial piety' may not be as strong then and may be perceived differently by the younger generation. In some cases, respondents used the term 'sandwich generation' to explain the cultural changes in eldercare and to describe their current/future circumstances. The term 'sandwich generation' originally referred to a generation of people between 45 and 65 who care for their ageing parents, whilst providing support for their own maturing children (Miller, 1981). Brody (1981:471) also describes the term as referring to 'women in the middle' - 'in middle age and in the middle from a generational standpoint' - caring for both their older parents and their own children. However, respondents seemed to perceive the term differently as 'in the middle of cultural transition' in eldercare in that they provide care and financial support for their older parents without expecting the same level of support from their own children. Four respondents who referred to the 'sandwich generation' were in their late 40s or $50 \mathrm{~s}$; two were in their early 30 s with young children. As respondents were asked to anticipate their old age, their reference to 'sandwich generation' may include their future as well as present circumstances.

About two thirds of respondents said they did not want to live with their parents-in-law in the future but felt obliged to do so. However, they did not perceive that their children would have 
the same feelings of obligation and filial piety towards older parents/parents-in-law as they do. More than a half of respondents argued they did not want to be a 'burden' to their children, while others emphasised 'being independent' from their adult children. Duna, who is 57 years old with two grown-up children, stressed this sense of independence in describing her plans for old age:

I do not want to live together with my son or daughter when I am older. I don't think they would like that either. We are like the 'sandwich generation'.... I think I should be responsible for old age myself. It would be good if government can support eldercare in general, but it is mainly my responsibility to plan for my old age.

According to the Korean Women's Development Institute's (2016c) brief on gender and care, the proportion of people opting for 'being independent' in old age increased from 11.9 per cent in 2008 to 18.9 per cent in 2016 , although a higher proportion chose family support and care as a solution (30.8\% in 2016). Independence in old age was important to many participants in this study, especially for younger generations. More than a half of respondents clearly argued the importance of 'being independent' of and not being 'burden' to their adult children, while generally agreeing with the ideal of filial obligation when care was needed for their own older parents/parents-in-law.

Interestingly, about two third of respondents perceived that their ideas about filial obligation and living with their adult children might differ from those of their parents-in-law, stemming from traditional ideas of sons'/daughters-in-laws' responsibility for parents in old age. For most respondents, living near to parents-in-law (rather than in the same house) was a preferred option, although they doubted that their husbands and parents-in-law would approve of it, as aforementioned.

\section{Conclusion}

This article has explored the impact of Confucian gender ideology on working mothers' experiences of intergenerational exchange of care and support. It examined to what extent Confucian gender ideology influences the operation of intergenerational reciprocity within the Korean family. The interview data indicates that the traditional Confucian gender roles exerts a strong influence on women's role in the family, even within the dual-earner families, as 
working mothers continue to take more responsibility for their parents-in-law rather than their own parents (Sung, 2003). Also, sons (particularly the eldest) retain their important position in the Korean family with the persistence of the Confucian hierarchical order of filial obligation. Moreover, parents-in-law and husbands seem to have greater control over the decisions of working mothers with regard to supporting their own parents than the women themselves, who were expected to provide care and financial support for their parents-in-law. This demonstrates the strong influence of Confucian gender ideology on intergenerational reciprocity, whereby sons are assumed to have responsibility to provide for older parents financially, while daughters-in-law serve as caregivers. Furthermore, it was found that parents prefer to receive support from sons rather than daughters, as has traditionally been the norm in the Korean family. This shows the continuing influence of Confucian gender ideology through hierarchical principles of intergenerational reciprocity.

Additionally, the notion of care as woman's work does not seem to have changed significantly, as it is still women who take primary responsibility for family care. Therefore, married women in paid work may have to cope with both childcare and eldercare simultaneously. However, it was also evident that there were a number of grandparents providing care for their grandchildren when their children are at work. This may mean both younger and older married women end up carrying the burden of family care, in addition to paid work in the case of working mothers.

To meet the needs of working mothers and older people in Korea, policies for both childcare and eldercare have gradually improved since the 1990s. The introduction of 'daddy month' in 2016 has been particularly notable in encouraging fathers' involvement in childcare. Likewise, policies for eldercare have been reformed twice since 2008, including the introduction of LongTerm Care Insurance. However, policies need to be further improved to promote more equal sharing of paid and unpaid work between men and women, and to address the entrenched Confucian notion of care as a family responsibility. Also, for policies to be effective, it seems that policy change must be accompanied by cultural changes in relation to gender roles (Sung, 2014), as cultural shifts seem to occur at a slower pace than policy development.

Along with the continued tradition of Confucian gender roles, future changes are also foreseeable given that most respondents, anticipating cultural and social changes, such as increased awareness of the generational gap and the importance of being independent in old 
age, prefer not to rely on their children when they become older. Considering the social/cultural changes in intergenerational obligations, reliance on family support for eldercare may not be a reasonable option for Korean families in the future. Therefore, government policies that focus on the socialisation of care (both child and elder care) must be considered to meet the needs of working mothers as well as of grandmothers providing care for grandchildren.

\section{References}

Brody, E. M. (1981) "WWomen in the Middle and Family Help to Older People", The Gerontologist 21(5):471-480.

Gouldner, A. W. (1960) "The Norm of Reciprocity: A Preliminary Statement", American Sociological Review 25:162-178.

Graham, H. (1983) "Caring: A Labour of Love”, In Finch, J. and Grove, D. A Labour of Love: Women, Work and Caring (pp.13-30). London: Routledge \& Kegan Paul.

Hong, S. and Lee, I. (2014) "Father's Use of Parental Leave in Korea: Motives, Experiences and Problems", Gender Studies and Policy Review Vol. 7. (pp.55-69). Seoul: Korean Women's Development Institute.

Izuhara, M. (ed.) (2010) Ageing and Intergenerational Relations: Family Reciprocity from a Global Perspective. Bristol: Policy Press.

Joo, J., Mun, Y., Kim, Y., Kim, Y., Jeon, K., Song, C., Han, J., Kim, K., Eun, K. and Lee, J. (2016) Gender and Family Household Survey 2016. Seoul: Korean Women's Development Institute.

Kim, H. (2016) "Is Long-term Care Insurance in South Korea a Socialising Care Policy?", Critical Social Policy 36(4):630-648.

Korean Statistical Information Service (KOSIS) (2012) Labor Force Participation Rate. Daejeon: KOSIS.

Korean Statistical Information Service (KOSIS) (2016) Economically Active Population and Labor Force Participation Rate. Daejeon: KOSIS.

Korean Women's Development Institute (KWDI) (2016a) Gender and Law Brief. Seoul: KWDI.

Korean Women's Development Institute (KWDI) (2016b) "Work-family balance policy", KWDI Policy Recipe for Gender Equality, Vol. 1 (pp.1-8). Seoul: KWDI.

Korean Women's Development Institute (KWDI) (2016c) "Equal Participation and Responsibility: Reviewing Gender and Care", KWDI Brief, No.40:1-8., Seoul: KWDI.

Kwon, H. J. (2009) 'The Reform of the Developmental Welfare State in East Asia", International Journal of Social Welfare, 18:S12-S21.

Lee, J. K. (2005) "Neo-Familism and Women: The Modern Transformation of the Korean Family", in Chang, P. and Kim. E (eds.) Women's Experiences and Feminist Practices in South Korea (pp.155-175). Seoul: Ewha Woman's University Press. 
Lee, S. W. (2005) "Patriarchy and Confucianism: Feminist Critical Readings of Culture, Power and Subject", in Chang, P. and Kim. E (eds.) Women's Experiences and Feminist Practices in South Korea (pp.67-115). Seoul: Ewha Woman's University Press.

Lee, Y., Kwon, M. and Kim, S. (2015) Grandparents Providing Care for Grandchildren: Policy Proposal. Seoul: Korea Institute of Child Care and Education.

Lin, I. F., Goldman, N., Weistein, M., Lin, Y. H., Gorrindo, T. and Seeman, T. (2003) "Gender Differences in Adult Children's Support of Their Parents in Taiwan”, Journal of Marriage and Family 65(1):184-200.

Lin, J. and Yi, C. (2013) “A Comparative Analysis of Intergenerational Relations in East Asia”, International Sociology, 28(3):297-315.

Miller, D. A. (1981) “The 'Sandwich' Generation: Adult Children of the Ageing”, Social Work 26(5):419-423.

Ministry of Employment and Labour (MOEL) (2016) Maternity Leave and Benefits. Sejongsi: MOEL.

Ministry of Government Legislation (MOLEG) (2016) Reformed Law of Equal Opportunities and Work-Family Balance Support, Sejong-si: Ministry of Government Legislation.

Ministry of Government Legislation (MOLEG) (2017) Welfare Provision for the Elderly, Sejong-si: Ministry of Government Legislation. Available at: http://www.law.go.kr/lsInfoP.do?1siSeq=188084\#0000 (Accessed 5 May 2017)

Organisation for Economic Co-operation and Development (OECD) (2012) "Intergenerational Solidarity". OECD Family Database. Paris: OECD Publishing.

Organisation for Economic Co-operation and Development (OECD) (2015) Health at Glance 2015: OECD Indicators. Paris: OECD Publishing.

Organisation for Economic Co-operation and Development (OECD) (2016a) "Public Spending on Childcare and Early Education". OECD Family Database. Paris: OECD Publishing.

Organisation for Economic Co-operation and Development (OECD) (2016b) "Korea - Country Note”. Education at a Glance 2016: OECD Indicators. Paris: OECD Publishing.

Organisation for Economic Co-operation and Development (OECD) (2016c) "Fertility". OECD Factbook 2015-2016: Economic, Environmental and Social Statistics. Paris: OECD Publishing.

Ritchie, J., Spencer, L. and O'Connor W. (2003) "Carrying out Qualitative Analysis", in Ritchie, J. and Lewis, J. (eds.) Qualitative Research Practice (pp.219-262). London: Sage.

Ross, C. E. (1987) “The Division of Labor at Home”. Social Forces 65(3):816-833.

Schwarz, B. Trommsdorff, G., Kim, U. and Park, Y. (2006) "Intergenerational Support: Psychological and Cultural Analyses of Korean and German Women", Current Sociology 54(2):315-340.

Schwarz, B., Trommsdorff, G., Zheng, G. and Shi, S. (2010) "Reciprocity in Intergenerational Support: A Comparison of Chinese and German Adult Daughters", Journal of Family Issues 31(2):234-256.

Statistics Korea (2011) The Population of the Elderly in Korea. Daejeon: Statistics Korea. 
Sung, K. T. (1990) "A New Look at Filial Piety: Ideas and Practice of Family-centred Parent Care in Korea", The Gerontologist 30(5):610-617.

Sung, S. (2003) "Women Reconciling Paid and Unpaid Work in a Confucian Welfare State: The Case of South Korea", Social Policy and Administration 37(4):342-360.

Sung, S. (2013) "Gender and Welfare States in East Asia: Women Between Tradition and Equality”, in Izuhara, M. (ed.) Handbook on East Asian Social Policy (pp.266-286), Cheltenham: Edward Elgar.

Sung, S. (2014) "Work-Family Balance Issues and Policies in South Korea: Towards an Egalitarian Regime?", in Sung, S. and Pascall, G. (eds.) Gender and Welfare States in East Asia (pp.29-48), Basingstoke: Palgrave Macmillan.

Tronto, J. C. (1993) Moral Boundaries: A Political Argument for an Ethic of Care. New York: Routledge.

Tronto, J. C. (2011) "A Feminist Democratic Ethics of Care and Global Care Workers: Citizenship and Responsibility", in Mahon, R. and Robinson, F. (eds.) Feminist Ethics and Social Policy: Towards a New Global Political Economy of Care. Vancouver: UBC Press.

Walker, A. (ed.) (1996) The New Generational Contract: Intergenerational Relations, Old Age and Welfare. London: Routledge

Yu, H. (2016) "Grandparents Providing Childcare”, Gender Review 42:31-42.

Yu, H., Lee, S. and Hong, J. (2015) Grandparents Providing Childcare for Dual-earner Families: Policy Proposal. Seoul: Korean Women's Development Institute.

Zhan, J., Feng, Z., Chen, Z. and Feng, X. (2011) "The Role of Family in Institutional LongTerm Care: Cultural Management of Filial Piety in China", International Journal of Social Welfare 20:S121-134.

Zuo, D., Wu, Z. and Li, S. (2011) “Age and Intergenerational Exchange among Older Parents in Rural China”, International Journal of Social Welfare 20:S30-S46.

\footnotetext{
${ }^{\mathrm{i}}$ Korea refers to South Korea throughout this paper.
} 